\title{
Myocardial Tissue Characterization of Left Ventricular Reverse Remodeling in Ischemic Cardiomyopathy
}

\author{
Yoji Nagata, MD; Tetsuo Konno, MD, PhD; \\ Kenshi Hayashi, MD, PhD; Masa-aki Kawashiri, MD, PhD
}

$\mathbf{P}$ athological left ventricular (LV) remodeling, defined as maladaptive LV cavity enlargement and structural change, occurs after myocardial damage, which is characterized by the combination of myocyte hypertrophy, apoptosis and interstitial fibrosis. ${ }^{1}$ Pathological LV remodeling leads to the deterioration of $\mathrm{LV}$ ejection fraction (LVEF) and the development of functional mitral regurgitation, contributing to further remodeling and worse prognosis in patients with heart failure (HF). ${ }^{1}$ Reduction of LV chamber volumes with an improvement in LVEF due to optimized treatment is termed "reverse remodeling", ${ }^{2}$ which can be achieved by coronary intervention, medical treatment including angiotensin-converting enzyme inhibitors and $\beta$-blockers, cardiac resynchronization therapy and pressure unloading with LV assist device..$^{3-5}$ Reverse remodeling has been also observed in a wide variety of clinical settings including viral myocarditis, postpartum cardiomyopathy, or after removal of a cytotoxic agent (Figure) ${ }^{6}$ At the molecular level, reverse remodeling can be in part explained by the calcium handling alteration, decrease in apoptosis, ${ }^{7}$ improvement of mitochondrial function, ${ }^{8}$ and reduction of the extracellular matrix remodeling promoted by matrix metalloproteinases. ${ }^{9}$

\section{Article p 2513}

Although reverse remodeling has been associated with favorable prognosis in HF, not all patients experience this process. ${ }^{10}$ Furthermore, the predictors of reverse remodeling have not been fully clarified, which may be due to lack of information on myocardial tissue characteristics during reverse remodeling. From this point of view, cardiac magnetic resonance imaging (CMR) has the high spatial and temporal resolution and the high contrast with late gadolinium enhancement (LGE) to assess the pathological changes of myocardium in HF patients. Intriguingly, there is some evidence that CMR could be used to predict the occurrence of reverse remodeling in HF:10,11 the degree of myocardial fibrosis estimated on LGECMR could better predict reverse remodeling compared with that on endomyocardial biopsy in non-ischemic HF.11

In this issue of the Journal, Park et al present additional evidence for myocardial tissue characterization during reverse LV remodeling based on their single-center retrospective study in Korea. ${ }^{12}$ The authors carried out detailed investigation of CMR parameters after surgical coronary revascularization in
26 ischemic cardiomyopathy patients with severe LV systolic dysfunction (LVEF $<35 \%$ ). Reverse LV remodeling was observed in $20(77 \%)$ of the 26 patients $21 \pm 14$ months after coronary revascularization. As expected, absolute infarct mass did not change during the follow-up period in the reverse remodeling group, but relative infarct mass was significantly increased, due to reduction of myocardial mass in the segments with non-transmural infarction.

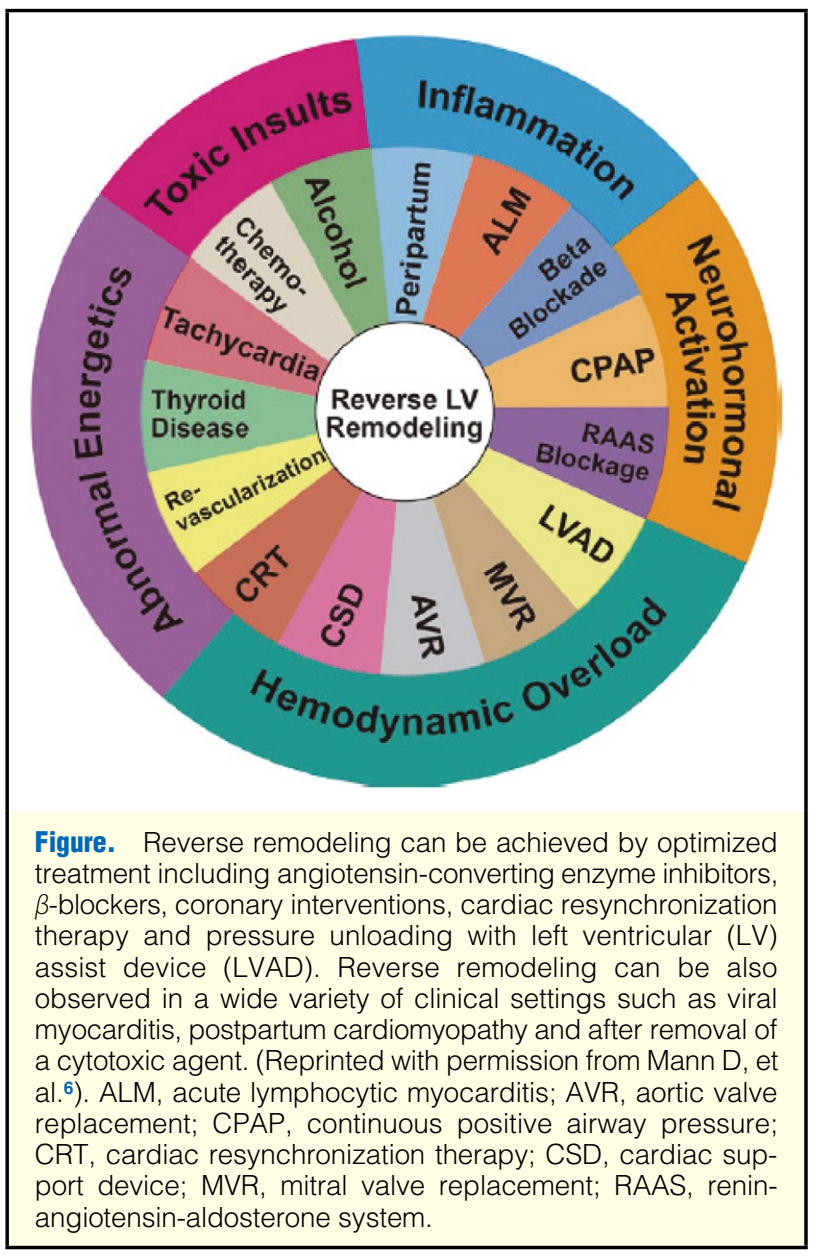

The opinions expressed in this article are not necessarily those of the editors or of the Japanese Circulation Society.

Received November 1, 2016; accepted November 2, 2016; released online November 10, 2016

Division of Cardiovascular Medicine, Kanazawa University Graduate School of Medicine, Kanazawa, Japan

Mailing address: Tetsuo Konno, MD, PhD, Assistant Professor of Medicine, Division of Cardiovascular Medicine, Kanazawa University

Graduate School of Medicine, 13-1 Takara-machi, Kanazawa 920-8641, Japan. E-mail: konnokontetsu@staff.kanazawa-u.ac.jp

ISSN-1346-9843 doi:10.1253/circj.CJ-16-1115

All rights are reserved to the Japanese Circulation Society. For permissions, please e-mail: cj@j-circ.or.jp 
Their main findings, unchanged infarct mass and reduction of myocardial mass during reverse remodeling, may not be surprising to cardiologists because this phenomenon has been well documented in previous pathological and echocardiographic studies. ${ }^{2}$ Nevertheless, this study is important because myocardial tissue characterization during reverse remodeling was beautifully visualized in a non-invasive manner, which may help cardiologists more deeply understand this dynamic process. Also, this study clearly demonstrated CMR-defined viable and non-viable myocardium. Regional reverse remodeling after revascularization was observed if regional transmural extent of LGE was $\leq 75 \%$. Although this small retrospective study did not provide predictive values for reverse LV remodeling, the cut-off for transmural LGE extent $\leq 75 \%$ may be used to predict the occurrence of reverse remodeling, which should be tested in a large prospective study in the future.

This study raises questions regarding the mechanism of reverse remodeling. Interstitial fibrosis plays a critical role in the development of pathological LV remodeling, ${ }^{13}$ although Park et al did not show whether the extent of interstitial fibrosis was reduced during reverse remodeling. This is because conventional LGE techniques are limited in the detection of diffuse interstitial fibrosis. ${ }^{14}$ The use of T1-mapping ${ }^{15}$ might be effective for investigating correlations between interstitial fibrosis and reverse remodeling. Further development in imaging technology, including in CMR to assess failed myocardium, may provide new insights into the mechanism of reverse remodeling and thus into treatment strategies for $\mathrm{HF}$ in the future.

\section{Acknowledgments}

We thank Professor Masakazu Yamagishi for his valuable comments on this manuscript.

\section{Conflict of Interest}

None.

\section{References}

1. Konstam MA, Kramer DG, Patel AR, Maron MS, Udelson JE. Left ventricular remodeling in heart failure: Current concepts in clinical significance and assessment. JACC Cardiovasc Imaging 2011; 4: $98-108$.

2. Koitabashi N, Kass DA. Reverse remodeling in heart failure: Mechanisms and therapeutic opportunities. Nat Rev Cardiol 2011; 9:
$147-157$.

3. Hoshikawa E, Matsumura Y, Kubo T, Okawa M, Yamasaki N, Kitaoka $\mathrm{H}$, et al. Effect of left ventricular reverse remodeling on long-term prognosis after therapy with angiotensin-converting enzyme inhibitors or angiotensin II receptor blockers and $\beta$ blockers in patients with idiopathic dilated cardiomyopathy. Am J Cardiol 2011; 107: $1065-1070$.

4. Gold MR, Daubert C, Abraham WT, Ghio S, St John Sutton M, Hudnall $\mathrm{JH}$, et al. The effect of reverse remodeling on long-term survival in mildly symptomatic patients with heart failure receiving cardiac resynchronization therapy: Results of the REVERSE study. Heart Rhythm 2015; 12: 524-530.

5. Wever-Pinzon J, Selzman CH, Stoddard G, Wever-Pinzon O, Catino A, Kfoury AG, et al. Impact of ischemic heart failure etiology on cardiac recovery during mechanical unloading. J Am Coll Cardiol 2016; 68: $1741-1752$.

6. Mann D, Barger PM, Burkhoff D. Myocardial recovery and the failing heart: Myth, magic, or molecular target? J Am Coll Cardiol 2012; 60: 2465-2472.

7. Castillero E, Akashi H, Pendrak K, Yerebakan H, Najjar M, Wang $\mathrm{C}$, et al. Attenuation of the unfolded protein response and endoplasmic reticulum stress after mechanical unloading in dilated cardiomyopathy. Am J Physiol Heart Circ Physiol 2015; 309: H459-H470.

8. Canseco DC, Kimora W, Garg S, Mukherjee S, Bhattacharya S, Abdisalaam S, et al. Human ventricular unloading induces cardiomyocyte proliferation. J Am Coll Cardiol 2015; 65: 892-900.

9. Felkin LE, Birks EJ, George R, Wong S, Khaghani A, Yacoub MH, et al. A quantitative gene expression profile of matrix metalloproteinases (MMPS) and their inhibitors (TIMP) in the myocardium of patients with deteriorating heart failure requiring left ventricular assist device support. J Heart Lung Transplant 2006; 25: 1413-1419.

10. Bertini M, Mele D, Malagù M, Fiorencis A, Toselli T, Casadei F, et al. Cardiac resynchronization therapy guided by multimodality cardiac imaging. Eur J Heart Fail 2016 July 13, doi:10.1002/ejhf.605.

11. Nabeta T, Inomate T, Iida Y, Ikeda Y, Iwamoto M, Ishii S, et al. Baseline cardiac magnetic resonance imaging versus baseline endomyocardial biopsy for the prediction of left ventricular reverse remodeling and prognosis in response to therapy in patients with idiopathic dilated cardiomyopathy. Heart Vessels 2014; 29: 784792.

12. Park EA, Lee W, Oh SJ, Kim KB. Magnetic resonance imaging of reverse remodeling after coronary revascularization in ischemic heart disease: Morphologic evaluation. Circ J 2016; 80: 2513-2519.

13. Rodrigues PG, Leite-Moreira AF, Falcao-Pires I. Myocardial reverse remodeling: How far can we rewind? Am J Physiol Heart Circ Physiol 2016; 310: H1402-H1422.

14. Konno T, Nagata Y, Teramoto R, Fujino N, Nomura A, Tada H, et al. Usefulness of electrocardiographic voltage to determine myocardial fibrosis in hypertrophic cardiomyopathy. Am J Cardiol 2016; 117: $443-449$.

15. Captur G, Manisty C, Moon JC. Cardiac MRI evaluation of myocardial disease. Heart 2016; 102: 1429-1435. 